\title{
Thomas Corneille, Les engagements du hasard
}

\section{Dario Cecchetti}

\section{OpenEdition}

\section{Journals}

\section{Edizione digitale}

URL: https://journals.openedition.org/studifrancesi/45794

DOI: 10.4000/studifrancesi.45794

ISSN: 2421-5856

\section{Editore}

Rosenberg \& Sellier

\section{Edizione cartacea}

Data di pubblicazione: 1 octobre 2007

Paginazione: 438

ISSN: 0039-2944

\section{Notizia bibliografica digitale}

Dario Cecchetti, «Thomas Corneille, Les engagements du hasard», Studi Francesi [Online], 152 (LI | II) |

2007, online dal 30 novembre 2015, consultato il 24 novembre 2021. URL: http://

journals.openedition.org/studifrancesi/45794 ; DOI: https://doi.org/10.4000/studifrancesi.45794

Questo documento è stato generato automaticamente il 24 novembre 2021.

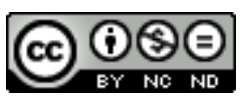

Studi Francesi è distribuita con Licenza Creative Commons Attribuzione - Non commerciale - Non opere derivate 4.0 Internazionale. 


\title{
Thomas Corneille, Les engagements du hasard
}

\author{
Dario Cecchetti
}

\section{NOTIZIA}

THOMAS CORNEILLE, Les engagements du hasard, a cura di Monica PAVESIO, Roma, Aracne, 2006, pp. 145.

1 Thomas Corneille è veramente il grande trascurato del teatro francese del Seicento. È vero che a partire dagli anni Settanta si sono susseguite varie edizioni, alcune eccellenti, di pièces isolate (Timocrate, a cura di Y. Giraud, 1970; L'Amour à la mode, a cura di C. Cosnier, 1973; Stilicon, a cura di C. J. Gossip, 1974; Camma, a cura di K. Cameron, 1977; Ariane, a cura di J. Truchet, 1986, La Devin eresse, a cura di J. Truchet, 1992; Le Geôlier de soi-même, a cura di E. Montet, 1995; Le Festin de Pierre, a cura di A. Niderst, 2000). Tuttavia, sarebbe auspicabile che fosse messa in cantiere un'edizione critica dell'intero corpus, per quanto imponente, di Thomas (così come si è finalmente fatto con altri autori, per esempio Rotrou o Tristan), giacché si tratta di un autore 'testimone' dell'evoluzione teatrale del Seicento, per uno spazio che copre una cinquantina d'anni di produzione drammatica: un autore, definito felicemente da David A. Collins (1966) a proteist dramatist, che ha segnato - e forse anche accarezzato - le mode e i gusti del pubblico, soprattutto nell'ambito di quella drammaturgia romanesque e galante che trova in lui - volgarizzatore del genere più ancora del grande Pierre - un modello che diventa, sì, stereotipo, ma che impone un linguaggio che sarà a un certo momento canonico; un autore, anche, sperimentatore, e mediatore, proprio in quanto sperimentatore, di testi europei trasmessi alla cultura francese. Senza contare l'impatto che ha, insieme a Quinault, sul genere della tragédie en musique, genere che rappresenta veramente la grande innovazione del teatro europeo del Sei e Settecento.

2 Per il momento, è benvenuta l'edizione critica, con minuzioso commento, della prima opera teatrale composta da Thomas (pubblicata nel 1657, ma rappresentata in data 
incerta tra il 1647 e il 1650): si tratta di una commedia nata come imitazione di Los empeños de un acaso di Juan Pérez de Montalbán, all'epoca attribuita a Calderón. M. Pavesio, che a partire dal suo libro su Calderón in Francia (Alessandria, Edizioni dell'Orso, 2000: cfr. questi «Studi», 139, 2003, pp. 125-126) ha approfondito e arricchito un discorso sull'ispanismo nel teatro francese del xvii secolo, pubblica e studia la commedia di Thomas Corneille evidenziando non solo il nesso con il modello spagnolo, ma anche la complessità di elaborazione del testo francese che, se in una prima redazione riprendeva soltanto Los empeños, nel testo finale contamina la pièce di Pérez de Montalbàn con una commedia calderoniana, Casa con dos puertas, mala es de guardar. M. Pavesio ricostruisce le vicende della composizione della commedia, risultato «di dieci anni di rimaneggiamenti, dieci anni importanti nella mentalità francese, che vedono la nascita e lo sviluppo dell'ideologia preziosa». Nell'introduzione viene messo molto bene in evidenza il ruolo sia della préciosité sia del contesto francese, negli sforzi di adeguamento delle fonti - fonti diverse proprio per questa volontà di rispecchiare le 'mode' culturali e sociali degli anni Cinquanta del Seicento - e nell'attenzione all'unità stilistica della pièce. Inoltre un'accurata repertoriazione di testi ricostruisce la fortuna non solo francese ma anche italiana delle commedie spagnole in questione, e ricompone così un quadro che fa da sfondo a quel gioco di intertestualità che è fondamentale nel teatro del Seicento. Intertestualità che continua ben oltre la pubblicazione della commedia di Thomas: basti pensare che quest'ultima sarà l'intermediaria fra le due commedie spagnole e il romanzo di Edme Boursault, Ne pas croire ce qu'on voit (1670). Il gioco di intertestualità nel nostro caso si complica, in quanto nella genesi lunga e laboriosa degli Engagements du hasard confluisce non solo l'influsso delle due commedie spagnole ma anche quello di una commedia dell'arte rappresentata in Francia da commedianti italiani, la quale a sua volta era una ripresa dei testi spagnoli. Le annotazioni puntuali al testo rendono conto di questo intrecciarsi di modelli e fonti. 